\title{
REQUIREMENTS FOR MEMBER INSTITUTES UNDER THE MINISTRY OF DEFENCE TO IMPROVE THE TRAINER QUALITY IN THE CURRENT CONTEXT OF EDUCATION AND TRAINING REFORM
}

\section{Cuong Ngoc Nguyen}

\section{Article History}

Received: July 16, 2020

Accepted: August 18, 2020

Published: September 30, 2020

\author{
Keywords \\ Lecturing staff, institutes, \\ Ministry of National \\ Defence, quality \\ improvement requirements
}

\author{
Logistics Academy - Ministry of Defence, Vietnam \\ Email: cuong.hvhc@gmail.com
}

\section{INTRODUCTION}

Deeply aware of the views and guidelines on fundamental and comprehensive reform of Education and Training in the spirit of Central Resolution 8, Session XI, the targets set out for the military requires intensive continuation of systematic planning and reform of Military institutes and schools, as the Ministry of National Defence (2013) set the goal for "comprehensive innovation, creating a fundamental and solid change in the quality and effectiveness of education, training and scientific research. To train professional and technical staff members with strong political skills and absolute loyalty to the Party, the Homeland, and the People; to possess creative thinking, sufficient qualifications and knowledge of military, politics, science, and technical expertise; to meet combat requirements in the new high-tech war conditions". The above goal has called for the academies under the Ministry of National Defence to respond to new requirements in developing the faculty (lecturing staff), in which it is necessary to ensure the appropriate quantity, a reasonable structure, and the continuous commitment to a high quality that contributes to the steady development of the military's education and training career among their lecturing staff.

The article identifies several requirements for academies under the Ministry of National Defence on improving the quality of faculty staff in the current context of education and training innovation.

\section{LITERATURE REVIEW}

In recent years, there have been various scientific research works on improving the quality of teaching staff at both Vietnamese and international universities, typically:

Berliner (2005) and the Ministry of Education of Singapore (2017) both emphasize that a qualified teacher must possess all three components: knowledge, skills and attitude. Only when these three elements are in place can the lecturers well fulfill their roles and duties. Firstly, knowledge refers to the capacity of thinking, including the necessary basic competencies for the profession such as the ability to grasp the problem, collect information, analyze, conclude and evaluate. Secondly, skills are the abilities to turn knowledge into actions, which, for teachers, are classified into practical application and creative application skills. However, the Ministry of Education of Singapore (2017) has developed a set of standards based on the competency framework of university lecturers, divided into four main groups (also known as competency clusters): fostering knowledge; enlightening the heart and mind; understanding oneself and others; and collaborating with others.

According to Vu Duc Le (2016), the quality of lecturing staff is not only reflected in the qualifications and capacity of teaching, scientific research and service activities but also in the ability to foster learners' personality. Nguyen Phuong Thao (2019) emphasizes that the quality of lecturers was considered a key factor in determining the quality of education; as in the era of globalization, the lecturing staff's role is subjected to drastical change in terms of both quality and quantity; and lecturers must become professional, creative, self-critical educators with an independent mindset, capable of providing active cooperation, effective support, and new insights to learners. 
When discussing the current situation of lecturing staff development, according to Pham Thi Diem (2018), the policy of developing faculty's human resources in higher education institutions is a system of public policies issued by the state to regulate the issues arising in the process of developing human resources for the faculty with specific objectives, methods and solutions. Ngo Quang Truong (2019) emphasizes that universities need to develop and apply specific mechanisms and policies based on practical conditions; focus on building magnet schools; improve the qualifications, skills to access and applying modern science and technology, etc. Particularly in the case of military academies, regarding lecturing staff based on capacity, Dinh Xuan Hanh (2018) pointed out the influencing factors to the development of lecturing staff, especially emphasizing the issue of awareness; planning; recruiting, training lecturers, with special attention to the quality and capacity of lecturers in the current context. According to Vu Xuan Tien (2019), the development of faculty staff requires military academies to raise awareness of the position, role and necessity of staff development, resulting in the appropriate selection, provision, training and fostering process to improve the qualifications and capacities of lecturers, along with the effective implementation of remuneration policies.

With approaches from different perspectives, many other scientific works have provided a multi-dimensional insight on the research topic. However, there is no in-depth research on some of the requirements posed by the member institutes under the Ministry of National Defence to improve the quality of lecturing staff in the current context of education and training reform.

\section{RESEARCH METHODS AND RESULTS}

\subsection{Research methods}

The article employs the qualitative research method, consolidating and analyzing theoretical and practical resources related to improving the quality of lecturing staff; official documents, resolutions, circulars and decisions of the Party, the State, the Central Military Commission and the Ministry of National Defence; research works related to the research topic such as scientific articles, scientific reports, and monographs. Along with that, the article also uses desk research methods, summarizing the experience of academies in terms of developing lecturing staff, while researching and acquiring experiences in the actual implementation progress of building and developing the lecturing staff.

The subjects of study include 06 institutions under the Ministry of National Defence: the National Defence Academy, the Military Political Academy, the Army Academy, the Military Academy of Logistics, the Military Technology Academy and the Military Medical Academy.

\subsection{Research results}

\subsubsection{Quality of the lecturing staff of member institutes under the Ministry of National Defence}

The Law on Education (National Assembly, 2019) states that: "Educators are in charge of teaching and training in educational institutions. Educators who teach at preschool, general education, other educational institutions, at elementary and intermediate levels, are referred as 'teachers'; and educators who teach from college level upwards, are referred as "lecturers". Accordingly, "The faculty staff is a collection of lecturing and educational professionals organized into a force sharing the mission of teaching, training and conducting scientific research. The work of faculty staff is intellectual labor, scientific labor, special labor to create special products, that is the fully educated human".

Following the above approach, while lecturers play a decisive role in ensuring the quality of education and training, their role can only be fully realized when they are fully qualified. According to Dinh Thi Tram (2020), "the quality of lecturers is all attributes and characteristics that illustrate the qualifications, competencies, qualities as well as the degree of completion of assigned tasks including teaching, scientific researching, community missions or service activities." Thus, the quality of lecturing staff is made up of various factors, which shall remain consistent within the whole lecturing staff shown through the number; the organization structure; the process of constructing, developing, training and fostering staff; and the quality of each lecturer, including factors such as political qualities, ethics and lifestyle; qualifications, pedagogical capacity, scientific research capacity and working style. These factors are mostly concentrated in the performance results of the assigned responsibilities and tasks, as well as the prestige of the pedagogical team and the students' satisfaction with the lecturers, which is the most important measure to evaluate the quality of lecturing staff (through the results of pedagogical labor for the education and training mission).

From the above problem, we conceive that the quality of lecturing staff in the institutes under the Ministry of Defence is "the combination of values, factors formed by the organization size and structure of the staff; the qualities, professional capacity, the responsibilities and duties fulfilment results of lecturers; the recognition from colleagues; and the satisfaction of students that satisfy the requirements and tasks of education and training in each phase of development of the institutes". 
In recent years, the institutes under the Ministry of National Defence have taken thorough consideration in building and developing a comprehensive lecturing staff, ensuring the best pedagogical quality, especially in terms of professional qualifications, capabilities and experience, which shows gradual "standardization" according to regulations. However, the current situation shows that the level of "standardization" of the lecturing faculty in the Army Institutes has not fully kept up with the mission of developing education and training in the current context. Regarding this issue, according to the General Staff of the People's Army (2019), the proportion of qualified lecturers is not sufficient, many lecturers have yet gained practical experience for their training positions; several academies and schools are not active in training and developing lecturers, especially postgraduate lecturers; the percentage of lecturers meeting the standards of foreign languages, and information technology remains relatively low. Therefore, this is an urgent issue calling for member institutes under the Ministry of Defence to continue improving the quality of their lecturing staff.

3.2.2. The current context of education and training reform and its requirements for improving the quality of lecturing faculty in member institutes under the Ministry of National Defence

In the context that Vietnam is enhancing international integration, along with the rapid development of science and technology, education must be innovated more intensively and quickly. As the Industrial Revolution 4.0 has been making a substantial impact on the educational environment, reshaping the roles of teachers, learners and teaching methods, modern teaching will consist of new functions such as designer, catalyst, mentor and learning environment creator. The teaching method that focuses on developing critical thinking and skills, which is irreplaceable by machines, will become the core of modern education, where the training of human resources shall result in adaptability and flexibility to changes. Therefore, improving the quality of education and training is more important than ever before to promote the internal resources for the development of the country.

Facing the above situation, the Communist Party of Vietnam (2016) emphasizes the development of the contingent of teachers and administrators, meeting the requirements of education and training innovation, including the standardization of the contingent of educators according to each educational and training level. Thoroughly following the mission, the Prime Minister (2019) showed strong commitment to building a contingent of lecturers and managers of higher education institutions that ensure quality, proper organization structure, meeting the changing requirements, fundamentally and comprehensively reforming the education and training process for high-quality human resources, the national science and technology advances, the rise of entrepreneurship and innovation, ... This will create a driving force for the development of modern education towards standardization, modernization, socialization, democratization and international integration.

For the People's Army, the Communist Party of Vietnam (2016) determined the direction of development with: revolutionary, regular, elite, step by step modernization, with priority given to the modernization of several military services, armies and forces; to remain politically concrete, improve the quality of the overall combat strength, and devote absolute loyalty to the Homeland, the Party, the State and the People. On the other hand, considering the influence of the Industrial Revolution 4.0 on the development of Vietnamese military science, technology and art, military schools and academies must actively research, learn and approach the advanced, scientific and modern education and training methods, constantly innovate the training processes, programs, contents and methods; expand association network and training cooperation with domestic and international prestigious training institutions; actively research, consolidate documents and textbooks, adding new issues of modern military science and practical situations into the teaching and training syllabus. In the face of the above situation, the Ministry of National Defence (2016) requires that the institutes under the Ministry of National Defence need to continue to build and develop the lecturing faculty with a adequate quantity, reasonable structure and good quality, with the focus on building and developing lecturing staff with good qualities and morals, professional qualifications, skills, pedagogical capacity and teaching methods and good health, meeting the requirements of educator standards according to regulations of the State and the Ministry of National Defence.

3.2.3. Requirements for member institutes under the Ministry of Defence to improve the quality of faculty in the current context of education and training innovation

3.2.3.1. Thorough understanding and creative application of the viewpoints of the Party and the Central Military Commission on personnel work, education and training based on the practical situation of institutes under the Ministry of National Defence 
This is the most important requirement for improving the quality of lecturers and is also a part of the work of building a contingent of lecturing staff at academies under the Ministry of National Defence in order to successfully implement the mission of education, training and scientific research. In order to improve the quality of lecturing staff, it is required that the party committees of institutes directly under the Ministry of Defence must always integrate and observe the Party's views and principles on cadres and cadres work, in which the focus is on the Resolution. No. 26NQ/TW (Central Committee, 2018), Resolution No. 769-NQ/QUTW (Central Military Commission, 2012), Resolution No. 109-NQ/QUTW (Central Military Commission, 2019), Resolution No. 29-NQ/TW (Central Executive Committee, 2013).

The Central Executive Committee (2018) determined that the goal of building the People's Army cadres is to maintain the absolute loyalty to the Party, the Homeland and the People, the readiness to fight and sacrifice for the independence and freedom of the Nation and the happiness of the people; a sense of strict discipline and high combat strength; a reasonable size and structure, meeting the requirements of developing a revolutionary, regular, elite, step by step modernized Army force; from $20-30 \%$ of cadres being able to work in an international environment. The Central Military Commission (2019) also determined that it is necessary to build a contingent of independent, creative, and passionate research and lecturing staff in terms of research and application of science and technology, with good military practice, capacity and pedagogical methods, satisfying the task of training and fostering cadres. Accordingly, the institutes under the Ministry of National Defence must follow the directives and resolutions of the Party, the Central Military Commission and the Ministry of National Defence to focus on building and developing lecturing staff with strong political standpoint and quality, good morality; possessing professional qualifications, pedagogical and scientific research capacity; good health to respond to pedagogical activities in the military environment; and sufficient conditions to meet the educator position standards according to regulations of the State and the Ministry of National Defence.

3.2.3.2 Emphasizing the importance of developing and completing professional title standards according to the regulations of the State and the Ministry of Defence

On the basis of the regulations on standard professional titles of lecturers, which are clearly identified in InterCircular No. 36/2014/TTLT-BGDDT-BNV (Ministry of Education and Training - Ministry of Home Affairs), Circular No. 66/2017/ TT-BQP (Ministry of Defence, 2017),... in order to ensure compliance with the functions and tasks of each institute, to create motivation for faculty development, it is advised to: describe the position, functions and specific scope of responsibility for the general obligations of a professional lecturer title; clearly specifying the specific tasks, including a list of standards and criteria that each rank of professional titles of lecturers should possess in accordance with a certain complexity of each level; regulations on educational level, foreign language proficiency, information technology capacity, lecturer competencies required to perform tasks in the field of professional activities, demonstration of the application of knowledge and skills equipped through training and working experience to ensure the proper implementation of teaching and scientific research tasks according to professional requirements; prescribing the standards of lecturers' training qualifications expressed through diplomas, certificates and requirements to each type of lecturers' professional titles and regulations to each specific specialty or field of expertise.

3.2.3.3. Regularly ensuring sufficient quantity, reasonable organization structure, increasing quality to meet the immediate and long-term missions of the innovation of education and training in the army

In order to ensure that lecturers are sufficient in quantity with a reasonable structure, the institutes need to ensure a sufficient number of lecturers in the payroll. The organization of lecturing faculty in academies under the Ministry of Defence will be the fundamental factor to create the completeness and strength of the faculty. Based on the direction and objectives of building the contingent of military lecturers in general and the organization of lecturing staff at academies under the Ministry of National Defence in particular, the academies shall work on proactive preparation and implementation of a plan to recruit, select, foster, arrange the lecturing staff to always ensure a sufficient quantity according to requirements and missions, striving to have a reserve force according to regulations. Regarding the structure of faculty staff, the educational level structure of the faculty is recommended to include bachelor's, master's and doctoral degrees, in which it is necessary to increase the proportion of lecturers with postgraduate qualifications (especially doctoral degrees); the lecturing staff's title structure includes teaching assistants, lecturers, main lecturers, senior lecturers, associate professors, and professors. The professional structure of faculty staff must ensure the rationality between faculties and subject groups on the basis of functions, tasks and workload of teaching and scientific research. 
Regarding the quality of lecturing staff, in order to meet the requirement of "standardizing" the contingent of teachers in the Army, the Central Military Commission (2019) identified and ensured that from present to 2030, the target for $100 \%$ of teachers with postgraduate qualifications should be achieved to meet the prescribed titles (in which the doctorate proportion is $25 \%$ or more), and $100 \%$ of the teachers should have passed the commanding position, managing the unit following the objectives and training requirements of each object. Therefore, when carrying out the progress in building, developing and improving the quality of faculty staff in institutes under the Ministry of National Defence, it is necessary to ensure the comprehensiveness and synchronization, in which enhancing the training of lecturers for both political qualities, ethics, lifestyle and working style; constantly improving qualifications, pedagogical capacity, scientific research capacity, ability to use foreign languages and apply information technology in pedagogical activities.

3.2.3.4. Fully implementing the stages and steps in the process of building and developing the lecturing faculty, closely combining the training of the institutes with the self-training of the staff

Improving the quality of lecturing staff at the academies under the Ministry of Defence is a very meticulous process, requiring good implementation of stages and steps from acquiring resource, selecting lecturers to planning, training, using arrangement, management, evaluation and implementation of policies for faculty members to create a strict operating process to ensure the achievement of quality and efficiency. It is necessary to strictly and consistently comply with the principle that the Party, namely the unification of the direct and comprehensive leadership of the staff work and management of staff; standardization, tightening of discipline and ethics in parallel with institutional building, creating environment and conditions to promote innovation and creativity spirit of faculty members for the mission of education and training. Improving the quality of faculty staff must be placed in the overall process of building a contingent of cadres in the institutes under the Ministry of National Defence, attaching importance to the virtues and talents, with the virtues at the root. Specifically, stability and development must be ensured; and the task of promoting the roles and responsibilities of organizations and forces, first of all, lies in the responsibility of the Party Committee, the Board of Directors of institutes, the leading cadres, the heads of all levels and functional agencies. On the other hand, it is necessary to promote the activeness and self-awareness of each lecturer in self-study, self-research, training to improve professional quality and capacity, turning the cadre training and fostering process into the process of self-training and self-fostering to fulfill the requirements and assigned tasks. 3.2.3.5. Continuing to innovate and implement the employment benefit policy for the lecturing staff to create motivation and to preserve and attract talent to serve in institutes under the Ministry of Defence

In order to create a strong motivation to improve the quality of lecturers and maximize their creative potential that is potential for the innovation of Education and Training, it is becoming more necessary to implement the employment benefit policy worthy of the staff's efforts. Therefore, academies should adhere to the Circulars of the Government, the Ministry of Education and Training and the regulations and guidelines of the Ministry of Defence on the policies for military personnel, including policies for lecturing staff. It is recommended for academies to continue to study and renew employment benefit mechanisms and policies for the lecturers to ensure comprehensiveness, synchronization and consistency; develop appropriate policies to encourage and motivate the faculty mentally and physically; policies on training, fostering, assigning and employment benefit for lecturers as well as conditions for ensuring the implementation of those policies. On the other hand, in the incoming future, it is necessary to form additional financial support policies when lecturers have articles published in international scientific journals on ISI/Scopus list, journals with international standard number ISBNs, or scientific research topics and projects with output product published internationally to encourage and motivate lecturers to improve the quality of research and strive towards international standards.

\section{DISCUSSION AND CONCLUSION}

The lecturing staff of member institutes under the Ministry of National Defence is the decisive factor in the quality of education and training of the military, contributing to providing the army with qualified, competent officers who can implement the mission of building the army and defending the homeland. Therefore, in the process of improving the quality of lecturing staff in the current period, it is necessary to integrate thoroughly, implement seriously, apply creatively and flexibly the above requirements, in accordance with the functions and tasks of each institute. However, through the research study, we recommend that, at present, due to the increasing requirements of the education and training reform, especially in the context of international integration and approaching the Industrial Revolution 4.0, new issues have been raised that calls for further study to clarify both the theoretical and practical aspects on the 
quality of lecturing staff and improving the quality of lecturing staff. Therefore, the above results will contribute to providing the fundamental contents of some requirements for academies under the Ministry of National Defence to identify policies and solutions to improve the quality of lecturing staff in the new period.

\section{REFERENCES}

Berliner, D. C. (2005). The near impossibility of testing for teacher quality. Journal of Teacher Education, 56, 205-213.

Central Executive Committee (2013). Resolution 29-NQ/TW dated November 4, 2013 on fundamental comprehensive renewal of education and training, meeting the requirements of industrialization and modernization in socialist-oriented market economic conditions and international integration.

Central Executive Committee (2018). Resolution No. 26-NQ/TW dated May 19, 2018 The Seventh Conference of Session XII focused on building a contingent of cadres at all levels, especially at strategic level, with sufficient qualities, capabilities and prestige, on par with the missions.

Central Military Commission (2019). Resolution No. 109-NQ/QUTW dated February 11, 2019 on building a contingent of military personnel, especially at the campaign and strategic level to meet the requirements of the mission in the new situation.

Communist Party of Vietnam (2016). Document of the XII National Congress of Deputies, Office of the Party Central Committee.

Dinh Thi Tram (2020). The quality of lecturers at public universities in Hanoi city. Doctoral thesis in Human Resource Management, University of Labor and Society.

Dinh Xuan Hanh (2018). Developing lecturing staff in Military academies from a capacity-based approach. Vietnam Journal of Education, 4, 15-19.

General Staff of the Vietnam People's Army (2019). Thematic reports on the current situation of the contingent of lecturers and educational administrators in military academies and schools.

Military Central Authority (2012). Resolution No. 769-NQ/QUTW dated December 21, 2012 on the construction of a contingent of army cadres in the period of 2013-2020 and the following years.

Ministry of Defence (2013). Strategy to develop education and training in the army for the 2011-2020 period. People's Army Publishing House.

Ministry of Defence (2016). Circular No. 51/2016/TT-BQP dated 20/4/2016 of the Ministry of Defence promulgating the Regulation on Schooling work of the Vietnam People's Army.

Ministry of Defence (2017). Circular No. 66/2017/TT-BQP dated 30/3/2017 promulgating standards for expertise technical - professional officer titles in the Vietnam People's Army.

Ministry of Education and Training and Ministry of Home Affairs (2014). Joint Circular No. 36/2014/TTLT$B G D D T-B N V$ dated 28/1 1/2014 regulating codes and standards for professional titles of lecturing staff in public higher education institutions.

Ministry of Education, Singapore (2017). Educational Performance Management System - EPMS, 7(3), 5-10.

National Assembly (2019). Education Law No. 43/2019/QH14 dated June 14, 2019.

Ngo Quang Truong (2019). Practical lessons from the experience of improving the quality of faculty in Asian countries. Journal of Economics Asia - Pacific, 11, 42-44.

Nguyen Phuong Thao (2019). Solutions to improve the quality of training lecturers to meet the requirements of educational reform and industrial revolution 4.0. Journal of Science and Technology, 206(13), 41-47.

Pham Thi Diem (2018). Policies to develop human resources of lecturing faculty in Vietnamese universities towards sustainable development. Journal of Theoretical Education, 277 + 278, 50-57.

Prime Minister (2019). Decision No. 89/QD-TTg, dated January 18, 2019, approving the project to improve the capacity of lecturers and management staff of higher education institutions to meet the requirements of fundamental innovation in the area of education and training in the period of 2019-2030.

Vu Duc Le (2016). The quality of university faculty in Vietnam nowadays. State Management Magazine, 243, 69-72.

$\mathrm{Vu}$ Xuan Tien (2019). Develop the contingent of instructors at military schools to meet the requirements and missions in the new situation. Vietnam Journal of Education, 7, 132-135. 